This paper is published in the open archive of Mid Sweden University

DIVA http://miun.diva-portal.org

with permission of the publisher

Citation for the peer-reviewed published paper:

Norgren M, Edlund H, Wågberg L, Annergren G. Fundamental Physical Aspects on Lignin Dissolution. Nordic Pulp \& Paper Research Journal. $2002 ; 17(4): 370-373$.

URL to article at publishers site:

http://dx.doi.org/10.3183/NPPRJ-2002-17-04-p370-373 


\section{Fundamental physical aspects on lignin dissolution}

Magnus Norgren, Håkan Edlund, Dept. of Natural and Environmental Sciences, FSCN, Mid Sweden University, Sundsvall, Sweden, Lars Wågberg, Royal Inst. Technol., Dept. of Pulp \& Paper Chem \& Technol, Stockholm, Sweden and Göran Annergren, JAG Consulting, Sundsvall, Sweden

\begin{abstract}
Keywords: Kraft lignin, Bleached softwood fibres, Adsorption, Coagulation, Hydroxide concentration, Ionic strength, Temperature.

SUMMARY: The aggregation of diluted kraft lignin (KL) solutions was studied by turbidity measurements at elevated temperatures, various sodium chloride and sodium hydroxide concentrations. Since adsorptive processes usually precede self-aggregation in macromolecular systems as the solution conditions get worse, the interaction between KL and pulp fibres was also investigated. When treating samples of fully bleached softwood pulp fibres in KL solutions under various solution conditions, the light-absorption coefficient increased and the brightness was found to decrease rapidly above $\mathrm{pOH} 1$, as the temperature was elevated. At pOH 2 and $175^{\circ} \mathrm{C}$, the adsorption of $\mathrm{KL}$ was up to about $6 \mathrm{mg} \mathrm{g}^{-1}$. The results are also discussed theoretically in terms of lignin solubility and lignin coagulation.
\end{abstract}

ADDRESSES OF THE AUTHORS: Magnus Norgren and Håkan Edlund: Dept. of Natural and Environmental Sciences, FSCN, Mid Sweden University, SE-851 70 Sundsvall, Sweden. Lars Wågberg: Royal Inst. Technol., Dept. of Pulp \& Paper Chem \& Technol, SE-100 44 Stockholm, Sweden. Göran Annergren: JAG Consulting, Granbacken 14, SE-856 34 Sundsvall, Sweden

a Dissolution of lignin from wood under kraft cooking may roughly be divided into three main events; fragmentation of the lignin macromolecular structures, solubilisation of the macromolecules and, finally, restricted transport of lignin fragments through the walls of the pulp fibre. Whereas fragmentation has been studied extensively, solubilisation and transport out of the fibre wall during kraft cooking have not been given the same penetrating interest, in particular not the physicochemical aspects. Ionisation of phenolic groups and solution behaviour of kraft lignin (KL) fragments at cooking conditions are important issues in this respect and have therefore been important objects in our studies of the kraft cooking fundamentals.

It is well known that the dissociation of phenolic groups in KL can be followed by UV-spectrophotometry (AulinErdtman 1954). Furthermore, UV-spectrophotometric techniques may also be applied in accurate determinations of the content of free phenolic groups in KL samples (Gärtner et al. 1999). Indications that the dissociation of phenolic groups in lignin is temperature dependent have been presented earlier (Gustafsson, Teder 1969). Recently, by applying the techniques described above, it was observed that the degree of dissociation of phenolic groups in KL decreases, as the temperature is increased (Norgren, Lindström 2000). Moreover, from calculations considering the electrostatic contribution from a dissociating KL macromolecule, it has been found that the mean apparent $\mathrm{pK}_{\mathrm{a}}$ is shifted to higher values as the molecular weight of the KL increases (Norgren, Lindström 2000). The solution behaviour of KL, i.e. the tendency to self-aggregate (Lindström 1980; Rudatin et al. 1989; Norgren et al. 2001a) and/or adsorb (Sundin,
Hartler 2000), is highly dependant on the solution conditions. By considering the effects of the hydroxide concentration $(\mathrm{pOH})$ and the ionic strength together with the influence of the temperature on the KL dissociation process, a theoretical explanation of the KL solution behaviour, was recently proposed (Norgren et al. 2001a). Generally, adsorptive processes precede self-aggregation in polymer systems (Jönsson et al. 1999). Adsorption of KL on internal surfaces in the pulp fibres as well as self-aggregation of KL might occur under unfavourable solution conditions. If these phenomena take place in the fibre wall, it is obvious that the rate of delignification will decrease. This is both due to reduced solubilisation, but also due to other restrictions in the diffusive mass transport of $\mathrm{KL}$ fragments through the fibre wall, as proposed by Favis and Goring (1984) and $\mathrm{Li}$ et al. (1996). Since high temperatures, ionic strengths and hydroxide concentrations have been involved in pulping, it is very important to investigate KL solubility characteristics under conditions relevant to the real process. In this paper, some experimental and theoretical considerations regarding the fundamental physicochemical aspects on lignin dissolution and stability of lignin solutions under kraft cooking conditions will be presented.

\section{Materials and methods}

\section{Materials}

The pulp used in the adsorption study was a fully bleached (TCF) never-dried softwood kraft pulp (Celeste) from the Östrand mill, Sweden. The pulp was fractionated and only the longfibre fraction was used in the investigation. The initial brightness of the longfibre fraction was determined to $86.6 \%$ ISO

A commercial softwood KL (KLI, Indulin AT - lot $123 \mathrm{H} 0189, M_{\mathrm{n}}=1060 \mathrm{~g} \mathrm{~mol}^{-1}, M_{\mathrm{w}} / M_{\mathrm{n}}=5.2$ determined by SEC) was supplied by Aldrich. A softwood KL from Östrand mill black liquors (KLO, $M_{\mathrm{w}}=4400 \mathrm{~g} \mathrm{~mol}^{-1}$ determined by SEC), was precipitated by acidification to $\mathrm{pH} 2$ and rigorously washed with water and air-dried. Thereafter, the KLO was soxhlet extracted with pentane to eliminate the resins and fatty acids. The carbohydrate residues were removed by the following 2,4-dioxane:water (9:1) extraction (Froass et al. 1998). Finally, the KLO was dried and stored under reduced pressure.

\section{Methods \\ Preparation of $K \mathbf{L}$ solutions for the aggregation study}

The various kraft lignin (KL) solutions were prepared by a total addition of $0.012 \%(\mathrm{w} / \mathrm{w}) \mathrm{NaOH}$ in deionised water and after a few minutes, small portions of deionised water, up to about $50 \%$ of the desired total volume was added. The KL was allowed to dissolve over-night under gentle stirring. Additions of sodium chloride were made and, 
finally, the $\mathrm{pOH}$-value of the samples was adjusted by $\mathrm{HCl}$ or $\mathrm{NaOH}$. The samples were heated in a temperature controlled water or oil bath during 35 minutes and thereafter rapidly cooled in water.

\section{Detection of KL self-aggregation}

The turbidity was determined using a Hach RATIO/XR 43900 turbidimeter, operating at the wavelengths of visible light. Below $100^{\circ} \mathrm{C}$, all measurements were performed directly on the warm sample cuvettes. In case of higher treatment temperatures, samples were put in test tubes and carefully sealed by flame. After the heat treatment, the test tubes were chilled in a water bath, cut, poured into the cuvettes and measured. The difference in turbidity between a newly heated, still hot sample and a sample, first heated and thereafter chilled and stored at room temperature for several weeks, was found to be below $10 \%$.

\section{The adsorption study}

In solutions containing $0.5 \mathrm{~g} \mathrm{~L}^{-1} \mathrm{KLO}$ and $0.1 \mathrm{M} \mathrm{NaOH}$, fully bleached pulp was added to a concentration of $1.0 \mathrm{~g} \mathrm{~L}^{-1}$. The pulp fibre suspensions were gently stirred at room temperature for 120 minutes. Appropriate amounts of sodium chloride were added and $\left[\mathrm{OH}^{-}\right]$was adjusted by $\mathrm{HCl}$ or $\mathrm{NaOH}$ to in between $\mathrm{pOH} \in[1,3]$. Thereafter, 500 $\mathrm{mL}$ of the sample suspension were placed in autoclaves and rotated in an oil bath at a temperature interval $T \in[75,175]{ }^{\circ} \mathrm{C}$ during 35 minutes. The autoclaves were cooled rapidly in water and the pulp samples were filtrated. In the next step, the pulp samples were dispersed and washed three times at room temperature in solutions (1000 $\mathrm{mL}$ ) of equal composition as used earlier in the experiment (without KL). Thereafter, the washing procedure was repeated with deionised water $(2000 \mathrm{~mL})$.

\section{Brightness and $\boldsymbol{k}_{457}$-value determinations}

Hand-sheets were made according to SCAN C 11:95 and the brightness of these sheets was determined by Elrepho 2000 measurements, following SCAN P 3:93. The lightabsorption coefficients at $457 \mathrm{~nm}, \mathrm{k}_{457}$, reflecting the chromophores in lignin were calculated according to the Kubelka-Munk theory, assuming s=35.

\section{Determination of adsorbed amount of $\mathbf{K L}$}

The KL coverage of the hand-sheets was measured on a Varian Cary 50 Scan UV-spectrophotometer equipped with a Diffuse Reflectance Accessory (DRA). Calibration sheets were made from the pulp used in the experiments, dipped and equilibrated in KL solutions of various concentrations and finally dried under re-strain in open air. The analysis was performed at $\lambda=290 \mathrm{~nm}$, which was found to be the wavelength of maximum absorption for solid KL.

\section{Results and discussion}

\section{KL self-aggregation.}

Fig. 1 describes the phase behaviour of a $1.0 \mathrm{~g} \mathrm{~L}^{-1} \mathrm{KL}$ solution (Indulin AT). The unfilled dots represent samples that are stable, whereas the filled dots show unstable conditions where coagulation occurs. $\mathrm{pOH}$ is the negative

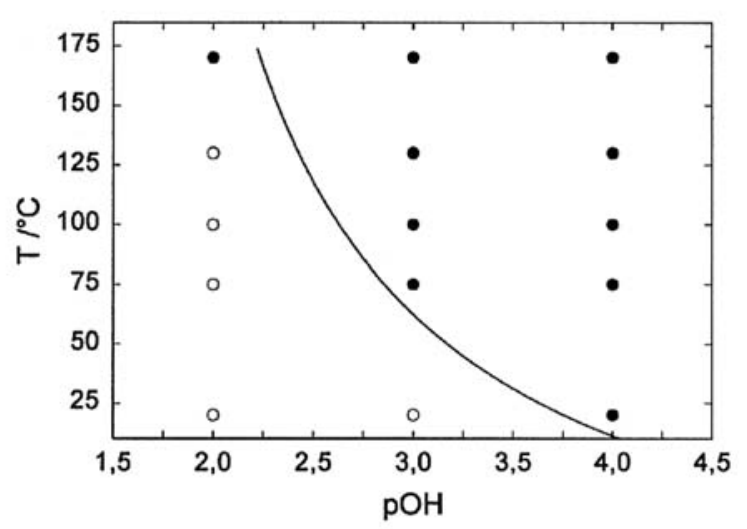

Fig. 1. Experimentally determined and calculated phase behaviour of $K L$ at various $p O H$ :s and temperatures. $[\mathrm{NaCl}]=1.0 \mathrm{M}$. Degree of $K L$ dissociation, $\alpha_{K L}=0.5$.

logarithm of the hydroxide concentration in the system. In opposite to the $\mathrm{pH}$-scale, at higher hydroxide concentrations $\left(\geq 10^{-4} \mathrm{M}\right)$ the $\mathrm{pOH}$-scale can be considered as independent of the temperature induced changes in the autoprotolysis constant of water. This accredits the use of $\mathrm{pOH}$ in describing the alkalinity at varying temperatures. The curve shown in Fig. 1 is derived from calculations of critical coagulations concentrations (CCC) based on the DLVO-theory (Norgren et al. 2001a). To the right of the curve, coagulation is predicted.

By combining the dissociation behaviour of phenolic groups in KL (Norgren, Lindström 2000) and the results shown in Fig. 1, a qualitative description of the phase behaviour at arbitrary solution conditions can be obtained. In Fig. 2, such an approach at three different temperatures is shown. The shaded area in the figure represents the solution conditions typical for the final part of conventional kraft cooks. The calculations indicate that when $\mathrm{pOH}-\left[\mathrm{Me}^{+}\right]$conditions in the digester is 'to the right' of an isothermal boundary line, coagulation of colloidal high molecular weight kraft lignin fragments starts to occur. In respect to the broken curve in Fig. 2, it should also be noticed that at room temperature, coagulation would not occur under the described conditions. This is an important finding and it certainly accredits the experiments to be performed at conditions relevant to the process if the solution

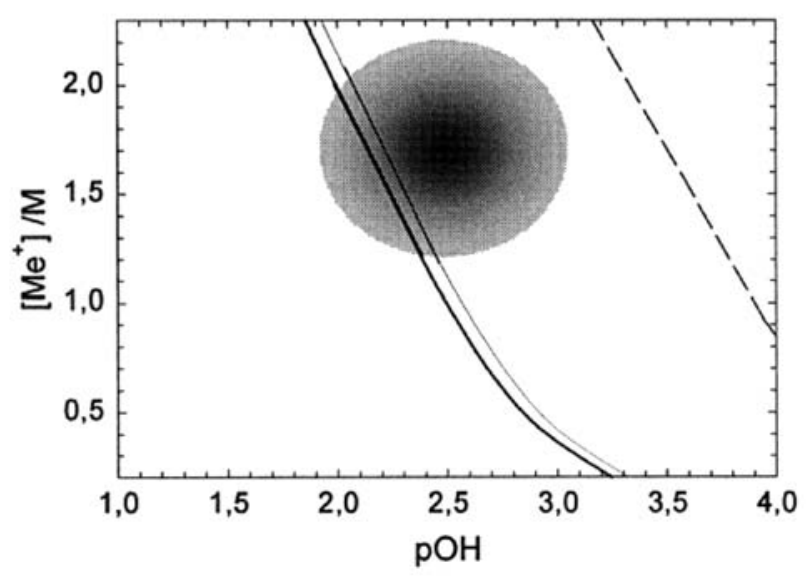

Fig. 2. Calculated stability isotherms calculated by using the DLVO-

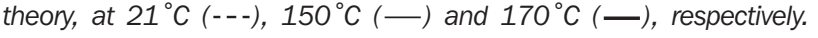
$\left[\mathrm{Me}^{+}\right]$denotes the concentration of monovalent cations. 
behaviour of KL is to be understood correctly. Furthermore, the results of both the experiments and the theoretical calculations show that in order to keep the KL soluble, a sufficiently high hydroxide concentration throughout the cook is a prerequisite for success. Nowadays, this is maintained in the new generations of modified kraft cooks. The theoretical descriptions of the KL phase behaviour shown in Figs. 1 and 2 are valid for high molecular weight KL fragments, which under certain conditions, for simplicity, might be treated as colloids. Theoretically, quantifiable information about the amount of phase separating KL is however difficult to obtain. This is due to the non-uniformity of the lignin material. Naturally, low molecular weight KL will always be present under the cook. Separately, this material shows a higher solubility than high molecular weight KL (Rudatin et al. 1989; Sundin, Hartler 2000; Norgren et al. 2001a; Norgren et al. 2001b). This is also predicted by polymer theories (Fleer et al. 1993; Jönsson et al. 1999). However, in polydisperse KL samples, co-coagulation of low molecular weight KL species is also observed (Rudatin et al. 1989; Sundin, Hartler 2000; Norgren et al. 2001b).

\section{KL adsorption onto pulp fibre surfaces.}

Due to the doubled entropy loss occurring when two soluble macromolecules are self-aggregating, adsorption usually appears ahead of the former process (Fleer et al. 1993, Jönsson et al. 1999). This is also an important aspect to consider in the fundamental discussion of lignin solubilisation. From a thermodynamical point of view, macromolecules dissolve spontaneously in a solvent only at a negative free energy of mixing $\left(\Delta G_{\text {mix }}<0\right)$. Concerning charged macromolecules, e.g. polyelectrolytes, the gain in entropy upon counterion dissociation generally gives the largest contribution to this process. In the theoretical treatment of polyelectrolyte adsorption by Scheutjens and Fleer (SF), four major entities are used to discuss and explain polyelectrolyte adsorption and these are $\chi, \chi_{s}, \sigma_{0}$ and $\mathrm{q}_{\mathrm{m}}$ (Fleer et al. 1993). The first two correspond to the Flory-Huggins parameter of polymers in solution and the adsorption energy parameter, respectively. The purely non-electrostatic $\chi$ parameter is dependent on the difference between the adsorption energy of a polymer segment and a solvent molecule. Simply stated, the adsorption is enhanced if the $\chi$ parameter has a value larger than 0.5 , since the polymer

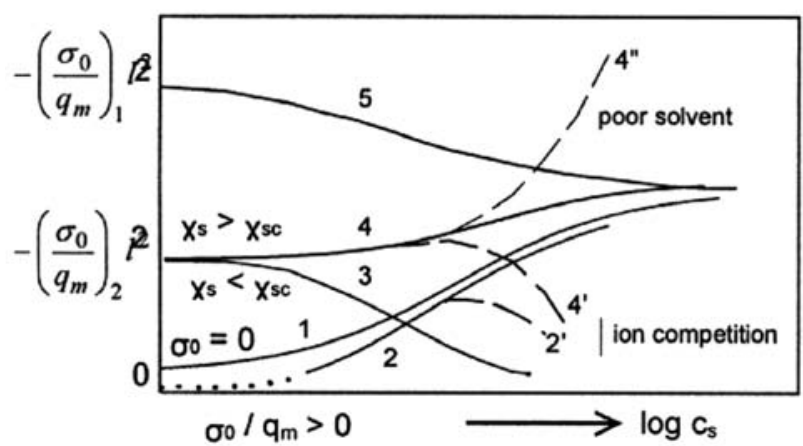

Fig. 3. Schematic overview of polyelectrolyte adsorption. Different polyelectrolytes and different surfaces were used for the numerical simulations and the adsorption is shown as a function of salt concentration, $c_{s^{*}}$ Redrawn from Fleer et al. (1993). then has a poor solubility in the solvent used. $\chi_{\mathrm{sc}}$ corresponds to the critical value of the $\chi_{s}$ parameter. The adsorption is thus also enhanced the higher the value of the $\chi$ parameter $\left(\chi_{\mathrm{s}}>\chi_{\mathrm{sc}}\right)$. The $\sigma_{0}$ and the $\mathrm{q}_{\mathrm{m}}$ denote the surface charge and the charge of a polymer segment, respectively. The theoretical predictions of the SF-theory for polyelectrolyte adsorption are summarised in Fig. 3. An anionic polymer system, e.g. the lignin-polysaccharide mixture (the fibre wall) under pulping conditions, is theoretically

(a)

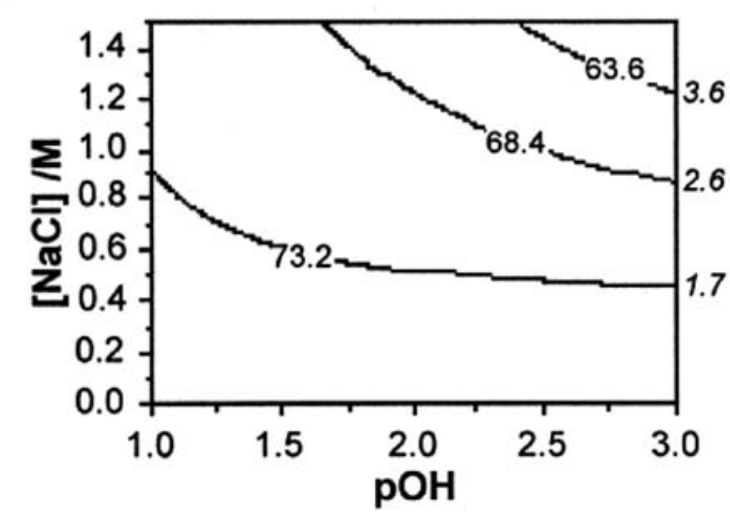

(b)

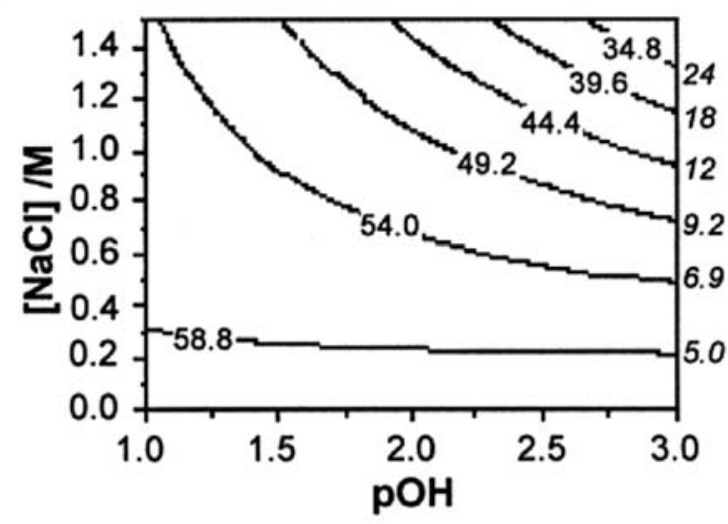

(c)

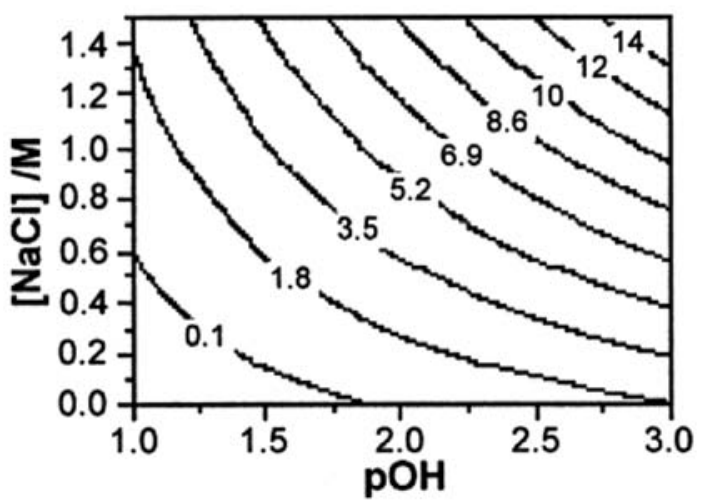

Fig. 4. Optical and surface chemical characteristics of bleached pulp fibres treated with kraft lignin solutions at different $\mathrm{pOH}: \mathrm{s}$ and $\mathrm{NaCl}$ concentrations. \% ISO brightness and $k_{457}$-values (italic) after treatment at (a) $75^{\circ} \mathrm{C}$ and (b) $175^{\circ} \mathrm{C}$. Adsorbed amount of $\mathrm{KL} \mathrm{(mg/g} \mathrm{fibre)}$ after treatment at $175^{\circ} \mathrm{C}$ is shown in (c). 
best described by curve 1 and 2 . Curve 2 depicts the scenario of both a charged surface and a polyelectrolyte, whilst curve 1 refers to polyelectrolyte adsorption on an uncharged surface. Fig. 4 describes the outcome of adsorption experiments of KL onto fully bleached softwood kraft pulp fibre surfaces at various solution conditions. At a low $\mathrm{NaCl}$ concentration and a high hydroxide concentration (low pOH), the adsorption is found to be low. If the $\mathrm{pOH}$ or the $\mathrm{NaCl}$ concentration is somewhat increased, the adsorbed amount of KL increases rapidly. Analogously, the SF-theory predicts that if the solvency of the polyelectrolyte is poor $(\chi>0.5)$, at low cs the electrostatic contribution will make the effective $\chi$ parameter $\left(\chi_{\text {eff }}\right)$ small and the polymer soluble. However, as discussed earlier, at very high $c_{s}, \chi_{\text {eff }}$ will increase and the polyelectrolyte might selfaggregate and, finally, precipitate. With a surface present, in this case the pulp fibre, an extensive adsorption can occur since the surface now acts as a nucleus for phase separation. In Fig. 3, this is exemplified by curve 4", but the equivalent scenario is also possible for systems represented by curve 1 and 2, i.e. the pulp fibre. The effect of high temperatures on the increase in KL adsorption found in Fig. 4, might be explained by the decreased KL dissociation found as the temperature increases (Norgren, Lindström 2000), which leads to that $\mathrm{q}_{\mathrm{m}}$ decreases. Consequently, the solubility parameter, $\chi$, will also increase and, thus, the adsorption is further promoted. The results obtained in the present investigation clearly points towards the fact that by approaching the kraft cook from a physicochemical viewpoint, much of the work regarding process development might be readily understood. Combined with conventional wood chemistry, it certainly would contribute to a further fundamental understanding of a very complex process. This brings about both new possibilities and challenges for the modern chemical pulping industry.

\section{Conclusions}

The concentrations of metal and hydroxide ions and the temperature affect the stability of kraft lignins under normal cooking conditions. Some part of the kraft lignin lies on or at the wrong side of the stability border. Doubtless, this will have a negative influence on the delignification. It is important to be aware of the stability threshold and thus, by an appropriate choice of the conditions in the digester, be on the correct side of the borderline of kraft lignin stability. Interestingly enough, modern cooking development heads in this direction. In order to further increase the understanding of the pulp fibre system under kraft cooking conditions, investigations of the kinetics of KL coagulation processes, as well as studies of adsorption of kraft lignin derivatives on pulp fibres and cellulose model surfaces, are underway. $\Omega$

\begin{tabular}{l}
\hline Acknowledgements \\
This work was financially supported by Mid Sweden University \\
and the Centre of Amphiphilic Polymers from Renewable \\
Resources (CAP). H.E. gratefully acknowledges The Swedish \\
Foundation for International Co-operation in Research and \\
Higher Education, STINT, for a postdoctoral fellowship.
\end{tabular}

Literature

Aulin-Erdtman, G. (1954): Spectrographic contributions to lignin chemistry. V. Phenolic groups in spruce lignin, Svensk Papperstidn. 57(20), 745.

Favis, B.D. and Goring, D.A.I. (1984): A model for the leaching of lig nin macromolecules from pulp fibres, J. Pulp Paper Sci. 10(5), 139.

Fleer, G.J., Cohen-Stuart, M.A. and Scheutjens, J.M.H.M. (1993): In "Polymers at Interface", T. Cosgrove and B. Vincent (Eds.), Chapman \& Hall, London.

Froass, P.M., Ragauskas, A.J. and Jiang, J.E. (1998): NMR studies Part 3: Analysis of lignins from modern kraft pulping technologies, Holzforschung 52(4), 385.

Gustafsson, L. and Teder, A. (1969): Alkalinity in alkaline pulping Svensk Papperstidn. 72(24), 795.

Gärtner, A, Gellerstedt, G. and Tamminen, T. (1999): Determination of phenolic hydroxyl groups in residual lignin using a modified UV-method, Nordic Pulp Paper Res. J. 14(2), 163.

Jansson, J., Palenius, I., Stenlund, B. and Sågfors, P.-E. (1975): Differences in colour and strength of kraft pulps from batch and flow cooking, Paperi Puu 57(5), 387.

Jönsson, B., Lindman, B., Holmberg, K. and Kronberg, B. (1999): "Surfactants and Polymers in Aqueous Solution", John Wiley \& Sons, Chichester.

Li, J., Phoenix, A. and MacLeod, J.M. (1996): Diffusion of lignin macromolecules within the fibre walls of kraft pulp. Part I, Pulp Washing '96, Vancouver, p. 139.

Lindström, T. (1980): The colloidal behaviour of kraft lignin. Part II, Colloid Polymer Sci. 258, 168.

Norgren, M. and Lindström, B. (2000): Dissociation of phenolic groups in kraft lignin at elevated temperatures, Holzforschung 54(5), 519.

Norgren, M., Edlund, H., Wågberg, L., Lindström, B. and Annergren, G. (2001a): Aggregation of kraft lignin under relevant conditions. Part I. Phase behaviour, Colloids Surfaces A, 194(1-3), 85

Norgren, M., Edlund, H. and Nilvebrant, N.-O. (2001b): Physicochemical Differences between Dissolved and Precipitated Kraft Lignin Fragments as determined by PFG NMR, CZE and Quantitative UV-Spectrophotometry. J. Pulp Paper Sci. 27(11), 359.

Rudatin, S., Sen, Y.L. and Woerner, D.L. (1989): In "Lignin: Properties and Materials", W.G. Glasser and S. Sarkanen (Eds.), ACS Symp. Ser. 397, 144.

Sundin, J. and Hartler, N. (2000): Precipitation of kraft lignin by metal cations in alkaline solutions, Nordic Pulp Paper Res. J. 15(4), 306.

Manuscript recived January 15, 2002 Accepted May 2002 